International Journal of Management Science and

Business Administration

Volume 1, Issue 6, May 2015, Pages 58-71

\title{
Impact of Goal Orientation Theory on Social Capital: The Implications for Effective Team Cooperation in Uzbekistan Textile Industry
}

\author{
Akmal Hudaykulov, Xu Hongyi, Mostak Ahamed Galib \\ School of Management Science and Engineering, Wuhan University of Technology, Wuhan, China \\ Email (corresponding author): ahudaykulov@yahoo.com
}

\begin{abstract}
The aim of the investigation was to identify and explain impact of performance orientation and learning orientation on the elements of social capital. A research model was based on goal orientation and social capital theory. A critical literature review on cooperation, social capital and goal orientation was conducted and the foundation for research was built. Ultimately cooperation within research and development teams in textile industry in Uzbekistan was assessed. Findings suggest there is a positive impact of learning orientation on social capital. However, there is no significant influence of performance orientation on any element of social capital. Furthermore, the study confirms the value of social capital in explaining cooperation. Along with these findings, integration of goal orientation theory and social capital theory in the cooperation context is a major contribution of the research. The study helps managers and team members to better understand the importance of social capital generation on projects and in organizations. The developed concept can be used as a framework for facilitating cooperation for governments, research institutions, academic institutions and companies. There are also implications in the domains of staffing, training, organizational culture and motivating employees.
\end{abstract}

Keywords: Goal orientation theory, Social capital theory, Performance orientation, Learning orientation, Uzbekistan

\section{Introduction}

Nowadays, with a help of many technologies we can cooperate online. Social interaction means like, email, video session, instant messaging and screen sharing can be found in workplaces of many people now. Still no matter what kind tools we use, all our interactions mostly depend on each other. Majority of tasks in organization is cannot be done without other people. Building strong relationships and enhancing social environment at workplace can help company to accomplish its goals. In life people are engaged in different communication processes with diverse purposes. Individual's behavior can be seen as one of main attributes while connecting with other people. Recent studies in field psychology and management science are used to explain behaviors. In psychology, person behavior lies as bedrock constructs underpinning a number of contemporary theories of behavior such as organizational 


\section{Akmal Hudaykulov, Xu Hongyi, Mostak Ahamed Galib \\ Impact Of Goal Orientation Theory On Social Capital: The Implications For Effective Team Cooperation In Uzbekistan Textile Industry}

citizenship behavior (Organ, 1988), theory of planned behavior (Ajzen, 1991), self-determination theory (Deci \& Ryan, 2000a, 2000b), self-efficacy theory (Bandura 1990). In our study we believe that human behavior can be also predicted with a goal orientation theory. However, there is no direct link that connects goal orientation with person interactions such, cooperation, social ties, trust and etc. Theoretical and empirical literature dealing with goal orientation theory (such as mastery and performance goals; Elliot, 1999, 2005; Meece et al., 2006) has proceeded in matching with little crossover of ideas. However, it would appear reasonable that particular goal orientation forms may align with particular social capital elements in such a manner as to maximize positive behavioral results. The rationale behind the present study is to examine potential synergies that may exist between forms of goal orientation drawn from goal orientation theory and types of social capital drawn from the social capital theory. As such, a study that examines the links between the two constructs not only offers theoretical contributions to the social capital literature, but also holds important practical implications for team members, improving social climate in cooperative engagement by emphasizing both goal orientation and social capital. To further explain the contextual relevancy of our research, we provide in the next section a brief description of the goal orientation with focus on learning orientation and performance orientation. Thus, we propose that goal orientation and social capital may predict the extent that members of R\&D team can interact with each other effectively in order to serve organization's main goals.

\section{Setting up theoretical framework}

\section{Defining goal orientation}

Goal-orientation theories were developed to explain achievement behavior in academic tasks. A goal is a cognitive representation that provides "the engine to move an organism to act" (Pintrich \& Schunk, 2002). A goal can guide an individual to pursue certain objectives in order to satisfy particular needs within a given environment. More specifically, a goal may be regarded as an integrated pattern of belief that leads to specific ways of engaging, acting, and responding to achievement situations. Goals explain not only why we pursue achievement tasks but also what type of standards we use to judge our performance.

Different individuals can approach the same task in the hope of achieving the same outcome, with different motivations for success. An individual's goal orientation can be viewed as the reason for their participation in task. Research over the past several decades has focused on two major classifications within this construct. One set of goals is related to learning, improving competence and mastering skills, while the other set of goals is related to demonstrating skills, comparing competence with others, and achieving performance standards.

Nicholls (1984) proposed that in some instances, individuals approach tasks with a desire to improve their competence in a given skill. Under these task involvement conditions, emphasis is placed on improvement with respect to past performances and internal (self) comparisons. Under ego involvement conditions, individuals approach tasks with a desire to demonstrate their competence with respect to the performance of others. The goal shifts from improvement and mastery to demonstration of performance. Nicholls believed that differences in the individual's approach would naturally affect other important motivational variables such as effort, task choice, and response to failure. Among other hypotheses, he proposed that when individuals had a low conception of their own ability, an ego involvement condition would cause them to withdraw from the task and would lower their performance. Dweck $(1986,2002)$ also recognized two distinct goal orientation patterns. She proposed that learning goals included individuals' desires to increase their competence or to learn or master something new. Performance goals included individual's desires to seek favorable judgments of their performance or to avoid negative judgments of their competence. For the purposes of this research, the author will use the term learning goal to describe those goals that are focused on improving skill and mastering tasks and the term performance goals to describe those goals related to demonstrating competence or avoiding negative judgments. To date, little empirical work has examined goal orientation in teams (Bunderson \& Sutcliffe, 2003, DeShon, Kozlowski, Schmidt, Milner, \& Wiechmann, 2004, and DeShon et al., 1999 are exceptions that examine goal orientation as a collective construct). The present study 


\section{Akmal Hudaykulov, Xu Hongyi, Mostak Ahamed Galib \\ Impact Of Goal Orientation Theory On Social Capital: The Implications For Effective Team Cooperation In Uzbekistan Textile Industry}

addresses the question of whether team interactions in terms of goal orientation can be used to predict team behavior and outcomes. Being high on learning orientation is associated with a belief that ability is flexible and can be developed with effort, practice, or both.

When it comes to achievement situations, individuals who are high on learning orientation typically attempt to increase their competence by developing skills and a mastery of the task. Effort is seen as a way of increasing one's ability and, in turn, one's performance. Being high on performance orientation is associated with a belief that ability is fixed and unchangeable. Individuals who are high on performance orientation often see little utility in devoting effort on tasks in which they perceive they have low levels of ability (Dweck, 1989). Heyman and Dweck (1992) suggested that individuals might hold one or both orientations. Button, Mathieu, and Zajac (1996) found support for Heyman and Dweck's notion that learning and performance goals are neither mutually exclusive nor contradictory.

\section{Social Capital}

The term "social capital" has come into wide use in recent years and it has become common for researchers and theorists to observe that the term is applied in so many different ways and to so many different situations that it is often difficult to say precisely what this term means (Portes 1998; Sandefur and Laumann 1998; Sampson, Morenoff, and Earls 1999). While social scientists have struggled to define the concept theoretically, they have also engaged in debates over how to operationalize and measure it. Level of analysis has posed a particular problem. Social capital has been located at the level of the individual, the informal social group, the formal organization, the community, the ethnic group, and even the nation (Coleman 1988; Portes 1998; Putnam 1995; Sampson et al. 1999). The popularity of the phrase has undoubtedly contributed to imprecision in the use of the concept. However, we suggest that the difficulty in defining, locating, and measuring social capital is at core a philosophical confusion of language, and not just a consequence of excessively wide application. The term "capital" refers to resources for investment. Financial capital consists of specific quantities of assets. Human capital, a metaphorical extension of financial capital, also consists of specific quantities of assets, in the form of skills or credentials. However, social capital, a third metaphorical construction, does not consist of resources that are held by individuals or by groups but of processes of social interaction leading to constructive outcomes. Therefore, we argue that social capital is not located at any one level of analysis and that it emerges across different levels of analysis. The confusion over the meaning of this term, then, is a consequence of a metaphorical confusion of a substantive quantity (capital) and a process that takes place through stages (embedded, goal-directed social relations). Locating and defining social capital is further complicated by the variability, conceptuality, and conditionality of the process. Stages of social relations that lead to constructive outcomes for one group of people or in one situation may not lead to constructive outcomes for another group or in another situation.

Different literature reviews, however, have pointed out that the introduction of the concept into current policy debates and discourses of development derived principally from the work of American scholars James Coleman and Robert Putnam (Adam \& Roncevic, 2003; Halpern, 2005; Fulkerson \& Thompson, 2008; Swain, 2003). Coleman developed the concept to explain how social organizations affect individual actions under the assumptions of rational-choice theory $(1988,1990)$. Under his 'individual-level theory of action', it is proposed that all social systems (e.g., systems of norms, trust, and authority) emerge from interactions between individuals who purposively engage with each other in order to access the resources they lack and that are of interest to them. Hence, all structural properties of any group or society are understood to constitute by—products of an actor's continuing pursuit of utility maximization.

The notion that social relations constitute a form of capital alluded to the additional utility that actors could extract from them in relation to the structural properties of the groups in which they operate. This definition, in consequence, is very flexible insofar as social capital only becomes evident by the benefits it generates, "just as the concept 'chair' identifies certain physical objects by their function, despite differences in form, appearance, and construction" (Coleman, 1988, p. S101). By the same token, the forms of social capital discussed by Coleman at that 


\section{Akmal Hudaykulov, Xu Hongyi, Mostak Ahamed Galib \\ Impact Of Goal Orientation Theory On Social Capital: The Implications For Effective Team Cooperation In Uzbekistan Textile Industry}

time - trustworthiness, obligations of mutual support, information sharing, and norms against malfeasancerepresented only a few expressions of an uncertain variety of social relations that could be considered 'capital' as long as they added value to individuals' actions.

According to Bourdieu (1980), social capital has two components: (1) the social relation itself; social capital is a resource linked with social networks and group membership: "the volume of social capital possessed by a given agent depends on the size of the network of connections that he can effectively mobilize" (Bourdieu, 1986); (2) the quality shaped by the total amount of the relationships between actors (Bourdieu, 1980). For the analysis of the social capital concept, Bourdieu (1980) did not suggest any economic methodology; social capital is an attribute used to increase the ability of an agent to advance his/her goals. Coleman (1988) made a step further to conceptualize social capital, stressing the multidimensional nature of the concept. "Social capital is defined by its function. It is not a single entity, but a variety of different entities, with two elements in common: they all consist in some aspect of social structures, and they facilitate certain actions of actors within the structure". Social capital relates to some aspects of social structure that "make possible the achievement of certain ends that would not be attainable in absence" (Coleman 1990: 302). Such definition is relevant in order to interpret empirical evidence found in the social capital and embeddedness literature, and represents a starting point for social capital measurement. Through the description of the wholesale diamond market in New York City, Coleman (1988) provided an example of the influence of social capital on economic performance. The peculiarity of this market lies in the exchange for inspection, from one merchant to another, of diamond bags worth hundreds of thousands of dollars. These exchanges take place without any formal insurance; thus, there is no formal guarantee that the merchant receiving these diamond bags will return them. The social structure based on family, community, and religious ties, represents an assurance that if someone does not respect economic obligations, the punishment will be the loss of these ties and expulsion from the market. Social capital allows the market to work and transactions to take place, otherwise it would be too expensive to establish insurance, and markets would not exist. Putnam (1993, 1995) looked at social capital as a community asset, defining social capital as the social structure that facilitates coordination and cooperation. Putnam's idea of social capital (2000: 19) refers to "connections among individuals, social networks and norms of reciprocity and trustworthiness that arise from them".

In sum, from the analysis of the proposed definitions, we conclude that there are two broad approaches to social capital; the first one considers social capital as the product of individual investment in the network of relationship (Coleman, 1988, 1990), the second one considers social capital as not individually produced, but as the result of the interaction among people (Putnam, 1993, 1995). According to the first approach, social capital is individually produced through individual investment on social relationships. According to the second one, social capital refers to the institutions, relationships, and norms that shape the quality and quantity of a society's social interactions (Putnam, 1993). "Social capital is not just the sum of the institutions that underpin a society, but it represents the glue that holds them together" (TheWorldBank 1999).

\section{Building a model: Impacts of Goal orientation (Performance \& Learning) on Social Capital}

\section{Performance orientation}

Performance orientation level of individual team members is important in raising the level of social capital for the benefit of the team as a whole. Thus, in professional relationship such as the project teams in which interdependence among members is critically high, other members' inability or incompetence would be detrimental to the team performance. Therefore, through performance goal oriented guidance team members are able to each other's behavior related to performance within a team or an organization. However, team members that are performance oriented tend to compete with others which in turn might have a negative impact on trust, reciprocity, building ties and identification. Among the components of social capital, performance orientation level seems to be mostly 


\section{Akmal Hudaykulov, Xu Hongyi, Mostak Ahamed Galib \\ Impact Of Goal Orientation Theory On Social Capital: The Implications For Effective Team Cooperation In Uzbekistan Textile Industry}

associated with trust issues more than any other social capital component. Moorman et al. (1993) Performance orientation has been extensively studied as an antecedent of trust in partnerships across a variety of contexts, including travel service (Mohan \& Ahlemann, 2013) and other highly knowledge-based services (Ifinedo, 2011). Crosby et al. (1990) showed that the perceived expertise of an insurance salesperson is a significant predictor for trust. Yu et al. (2013) in their study of corporate credibility found a positive relationship between performance orientation and trust. Furthermore, a competent service provider is known to influence an organization's performance and knowledge sharing by way of trust. However, Spake and Megehee (2010) diverted from trust and showed that perceived level of performance orientation expertise is positively related to the level of trust between partners. An assessment of performance goal orientation's impact on social capital is found to be highly significant (VandeWalle, 1997). In studies where goal orientation was carried, group membership identification was assumed to represent ones' orientation and the findings suggested that goal orientation reflects an enduring behavioral characteristic of social capital (Mueller \& Dweck, 1998). Theoretical support for the goal orientation surrounding instrumental and expressive ties has been raised in literature. Researchers have primarily examined goal orientation relationships with specific task-related ties and various performance outcomes on social capital, a study by Dweck and Leggett (1988) appear to reflect such construct. While these findings are capable in ascertaining individual variances in performance. The models proposed by Button et al. (1996) and VandeWalle (1997) highlight the significances to examine the goal orientation constructs to specifically address social capital validity issues. The following hypothesis are developed as a result of the above extensive analysis of the impact of performance orientation on social capital;

H1 Performance orientation has a negative impact on expressive ties

H2 Performance orientation has a negative impact on instrumental ties

H3 Performance orientation has a negative impact on trust

H4 Performance orientation has a negative impact on identification

H5 Performance orientation has a negative impact on reciprocity

\section{Learning Orientation}

Validation studies for the impact of goal orientation on social capital proposed a model of relationships surrounding the construct of learning orientation toward social capital particularly on trust. It illustrates goal orientation relationships among a number of dispositional constructs of social capital (Button et al., 1996; VandeWalle, 1997). Through such comprehensive examination of the relationship between goals orientation constructs with implicit theories of ability, work, fear of negative evaluation, and feedback-seeking tendencies that builds ties and trust within a team. Learning goal constructs in prior studies (Button et al., 1996; VandeWalle, 1997) were hypothesized to reflect differential relationships with each of the dispositional correlates toward social capital. The results of these validation studies reflect support for the hypothesized relationships on the conceptualizations of goal orientation and social capital in this study. Team members that tend to be learning oriented are more likely to share knowledge as a kind of reciprocity and identification to the team. The focus in this study is on individuals and their roles and relationships with other individuals within a team as their major unit of analysis of social capital influenced by learning goal orientation. The view that the actions of individuals and groups can be facilitated or dictated by the goals shared in a network, specifically by their instrumental and expressive ties that exist within a network or team.

Many socialists and political scientists view that social capital exists as an external factor that arises from the positive interactions that occur between individuals in a network deepened by the essence of learning orientation (Lesser, 2000). While, Adler \& Kwon, (2000) consider social capital from a learning perspective to be "a feature of the internal linkages that characterize the structures of collective actors and give them cohesiveness and its associated benefits. The findings from literature review suggest that individuals with a learning goal orientation reflect more positive orientations on several personal characteristics, which may also play a role in why they engage in more productive patterns of behavior compared to those with a performance goal orientation. The behaviors 


\section{Akmal Hudaykulov, Xu Hongyi, Mostak Ahamed Galib \\ Impact Of Goal Orientation Theory On Social Capital: The Implications For Effective Team Cooperation In Uzbekistan Textile Industry}

associated with goal orientation are the self-regulatory actions involving how effort is expended on tasks, while the outcomes examined have varied across learning and task contexts (Qianhong, 2004). Fisher \& Ford, (1998); Ford et al., 1998; VandeWalle et al., (1999) have found consistent support that individuals with a learning goal orientation outperform those with a performance goal orientation in comparison toward social capital construct. Learning orientation is increasingly becoming recognized as an important prerequisite for the survival and success of the organization's current and future, based on the shared value of social capital with a network, team or an organization (Dodgson, 1993). Learning theorists have often argued that learning orientation is beneficial to employees because it will increase the sense of identification, strengthens ties such as instrumental and expressive, where trust thrives and reciprocity and autonomy are embraced (Remedios \& Boreham, 2004). Social capital embedded in organizational capability emerges over time through a process of learning orientation (Levitt and March, 1988). Capability of the knowledge sharing based is considered to be one thing that is strategically important to create and sustain social capital value (Denisi et al., 2003). Sinkula et al. (1997) found there are three components of learning orientation is a commitment to learning, shared vision, and open-mindedness in developing a social capital shared among teams. The theoretical analysis above has facilitated to put forward the development of the following hypotheses;

H6 Learning orientation has a positive impact on expressive ties

H7 Learning orientation has a positive impact on instrumental ties

H8 Learning orientation has a positive impact on trust

H9 Learning orientation has a positive impact on identification

H10 Learning orientation has a positive impact on reciprocity

\section{Research methods}

The approach is quantitative research which questionnaire is designed from the theories and previous studies. Convenient data is collected from a 5 different organizations including 200 respondents in the Uzbekistan, since all the managers are willing to collect the questionnaires launched through the mail and website.

A survey method was applied and a questionnaire was developed on the basis of prior studies. Structural Equation Model is extrapolated by using Amos version 21.0 for Windows in analyzing the statistical values. The SEM approach involved the confirmatory approach to model specification. Structural Equation Modeling together with multiple regression was used to test the predictive value of our model. The questionnaire was designed in English and translated into Russian later on. Sentences requested both optimistic and pessimistic perspectives. The questionnaire was developed to obtain information about social capital, two types of goal orientation and the cooperation. It comprises three parts; part one requires a respondent to answer about his/her demographic data; in part two, the respondent has to indicate the extent to which he/she agreed or disagreed with formulated items related to the independent variables; Items were measured on a 7-point Likert scale.

The model generation started with descriptive statistics analysis, then, followed by a reliability test, validity test, normality test and structural model analysis to test the measurement model. The initial items included indicators proposed for the construct factors. All the latent variables were operationalized and measured with items that were validated by other researchers. In the research model goal orientation encompassing learning orientation and performance orientation are independent variables, whereas cooperation is a dependent variable. expressive ties, instrumental ties ,trust, reciprocity and identification sharing function both as independent and dependent variables depending on the analysis stage. The questionnaire was designed by modifying scales used in prior studies in order to increase the validity of the measurement instrument. All the latent variables were operationalized and measured with items that were validated by other researchers. In the research model goal orientation encompassing learning orientation and performance orientation are independent variables, whereas cooperation is a dependent variable. expressive ties, instrumental ties, trust, reciprocity and identification sharing function both as independent and dependent variables depending on the analysis stage. 


\section{Akmal Hudaykulov, Xu Hongyi, Mostak Ahamed Galib \\ Impact Of Goal Orientation Theory On Social Capital: The Implications For Effective Team Cooperation In Uzbekistan Textile Industry}

\section{Team cooperation}

Team cooperation was measured with the adjusted scale of Baruch and Lin (2012) who adopted the measurements for team performance from Stewart and Barrick (2000). The scale proved to be reliable with Cronbach's Alpha $(\alpha=$ .83). Both team behaviors and team outcomes make up team performance and were included in the original version of scale measuring. In our study we assessed cooperation quality and the extent to which they engage in cooperation.

\section{(1) Social capital items (trust, identification, ties, reciprocity)}

Social capital elements were assessed by adopting the scales used by Lin (2007), who it derived from the study of Wasko and Faraj (2000). In these studies all the items exhibited sufficient reliability and validity.

\section{(2) Goal orientation (performance and learning orientation)}

Performance and learning orientation were measured with scales adopted from Matzler and Mueller (2011). They adapted the measures of goal orientation taken from Mowen (2000).

Measure for performance orientation reflects the importance of outperforming others and winning, as well as the extent to which individual is result driven and enjoys competition. Scale for learning orientation reflects that individuals engage in various behaviors in order to share knowledge and learn. Cronbach's Alpha $(\alpha=.81)$ values of the adopted scales were of adequate level for performance orientation $(\alpha=.88)$, and for learning orientation $(\alpha=$ $.81)$, respectively.

\section{Results}

The analysis process was conducted in three main parts. First, the normality of data has been assessed in order to be able to continue with further analysis. In table the values for mean, standard deviation, skewness, kurtosis, minimum and maximum are shown.

\section{Assessment of measurement model}

The current study used a questionnaire for collecting data. Payne, Moore, Griffis, and Autry (2010) observed that 109 articles use social capital as the key research construct, rather than merely mention the term, and found that 80 articles in empirical research used questionnaires. Of the 80 reviewed articles, social capital was utilized as an independent and dependent variable. Explaining cooperation is a fundamental purpose for social capital studies. The model generation started with descriptive statistics analysis, then, followed by a reliability test, validity test, normality test and structural model analysis to test the measurement model. In the scale construct process, the questionnaire was reviewed based on the theoretical framework and the guidance of the experts from various universities. The questionnaire initially included items; after testing with reliability analysis, the variables were eliminated to 16 indicators. The four factors extracted were tested as individual scales to measure the extent to which multiple indicators represented the constructs. Cronbach's reliability alpha was calculated to assess the internal consistency for all scales. The result showed alpha range from .79 to .84 . The alpha on standardized items for all scales met the minimum level of acceptability.

\section{Structural model analysis}

In order to test the relationships of variables in our model a correlation analysis and multiple linear regressions were used. A Pearson product-moment correlation was run to determine the goal orientation impact on social capital. However, performance orientation illustrated negative correlation with almost all variables, performance orientation and trust in co-workers $(\mathrm{r}=-.060, \mathrm{n}=170, \mathrm{p}<.0005)$, learning orientation and performance orientation $(\mathrm{r}=-.018, \mathrm{n}$ $=170, \mathrm{p}<.0005)$, performance orientation and reciprocity $(\mathrm{r}=-.022, \mathrm{n}=170, \mathrm{p}<.0005)$, identification and performance orientation $(r=-.042, \mathrm{n}=170, \mathrm{p}<.0005)$, except expressive ties and performance orientation $(\mathrm{r}=.017$, 
$\mathrm{n}=170, \mathrm{p}<.0005)$ resulting in weak correlation between each other. Next we performed a multiple regression analysis, with all the outputs exhibited in the tables below. Using multiple regression analysis learning orientation has been confirmed as having impact on almost all elements of social capital. However the predictive value was not that high. The estimate and the standardized regression coefficients were explained in order to determine the validity of the hypothesized paths. The statistical significance of all structural parameter estimates are illustrated in figures, and shown in tables. Standardized estimates are used when comparing direct effects on a given endogenous variable in a single group study.

\section{SEM Goal orientation and social capital}

Since the measurement models were supported through the good fit indices, the structure models for this study were then used to investigate the relationships among the variables. The structural model reflecting the assumed linear, causal relationships among the constructs was tested with the data collected from the validated measures. The model fit indices were within the accepted thresholds: $\mathrm{CMIN} / \mathrm{DF}=18.03, \mathrm{GFI}=.54, \mathrm{CFI}=.19$, TLA $=.95$ and RMSEA= .41 .

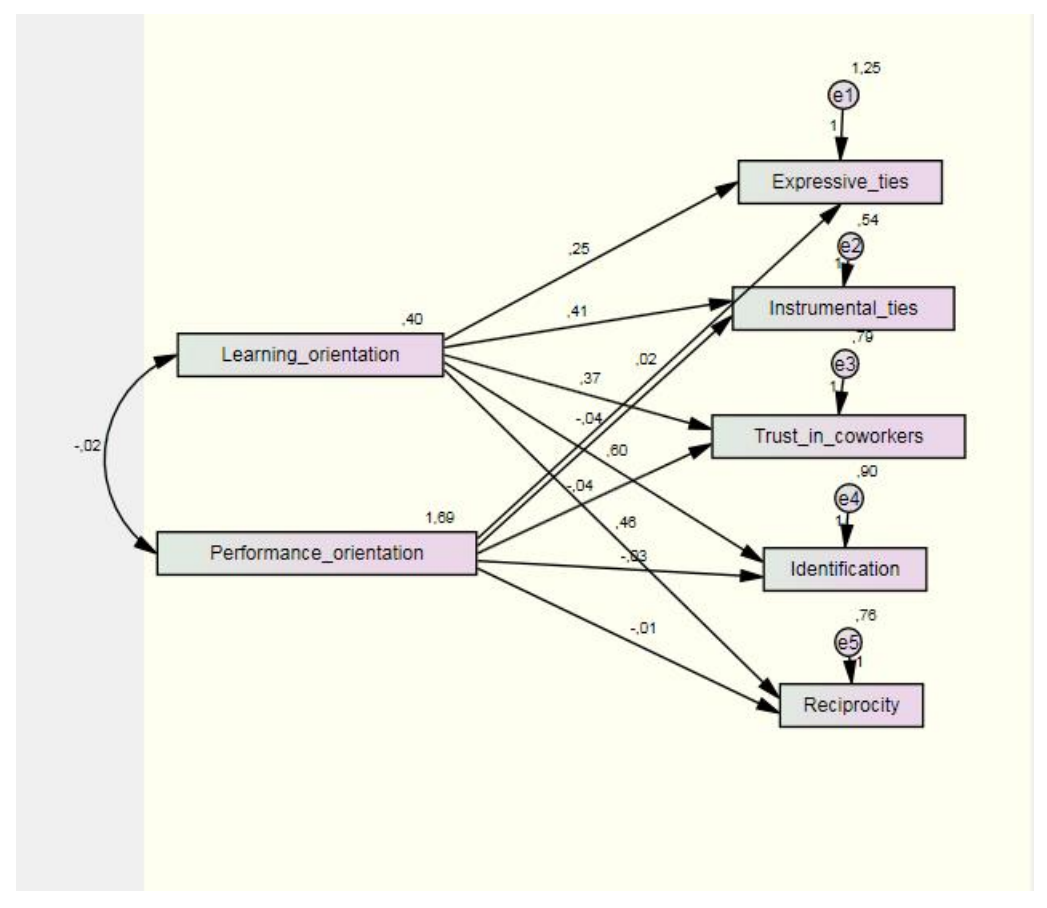

Figure 5-1 Structural Model Results

The estimate and the standardized regression coefficients were explained in order to determine the validity of the hypothesized paths. The statistical significance of all structural parameter estimates are illustrated in Figure 5-1. Standardized estimates are used when comparing direct effects on a given endogenous variable in a single group study. Table 5-2 shows that the critical ratio (CR) value is greater than 1.96 for a regression weight, and that the path was significant at the .05 level or better. In the standardized estimate column, three asterisks (***) indicate significance smaller than .001; two asterisks indicate significance at the level of .01. All paths in the hypothesized model are significant at the level of $.001, .01$, and .05 , accordingly. 
Table 5-2 Regression weights

\begin{tabular}{lrlrrrrr}
\hline & & & Estimate & S.E. & C.R. & P & Label \\
\hline Expressive_ties & $<---$ & Learning_orientation &, 254 &, 137 & 1,863 &, 062 & \\
Instrumental_ties & $<--$ & Learning_orientation &, 409 &, 090 & 4,558 & $* * *$ & \\
Trust_in_coworkers & $<---$ & Learning_orientation &, 368 &, 109 & 3,376 & $* * *$ & \\
Identification & $<---$ & Learning_orientation &, 595 &, 116 & 5,128 & $* * *$ & \\
Reciprocity & $<---$ & Performance_orientation &,- 011 &, 052 &,- 217 &, 828 \\
Reciprocity & $<---$ & Learning_orientation &, 458 &, 107 & 4,286 & $* * *$ & \\
Identification & $<---$ & Performance_orientation &,- 027 &, 056 &,- 488 &, 626 \\
Trust_in_coworkers & $<---$ & Performance_orientation &,- 039 &, 053 &,- 740 &, 459 \\
Instrumental_ties & $<---$ & Performance_orientation &,- 042 &, 043 &,- 958 &, 338 \\
Expressive_ties & $<---$ & Performance_orientation &, 017 &, 066 &, 264 &, 792 & \\
Note: $*$ p $<.05, * * \mathrm{p}<.01, * * * \mathrm{p}<.001$ & & & & & & &
\end{tabular}

The predictors of social capital showed a significant amount of variance in the full structural model; the lane flowing from learning orientation to expressive ties (standardized estimate $.13, \mathrm{C} . \mathrm{R} .=1.86, \mathrm{p}=.062$ ); the path flowing from learning orientation to instrumental ties (standardized estimate .09, C.R. $=4.56, \mathrm{p}<.001$ ); the corridor flowing from learning orientation to trust in coworkers (standardized estimate .11, C.R. $=3.37, \mathrm{p}<.001$ ); the lane flowing from the learning orientation to identification(standardized estimate $.11, \mathrm{C} . \mathrm{R} .=5.12, \mathrm{p}<.001$ ), the path flowing from the learning orientation to reciprocity (standardized estimate $.11, \mathrm{C} . \mathrm{R} .=5.12, \mathrm{p}<.001$ ) were significant.

However, the path flowing from performance orientation to reciprocity (standardized estimate .05 , C.R. $=-0.21$, $\mathrm{p}=$ .828 ); the track flowing from performance orientation to identification (standardized estimate .05 , C.R. $=-.49$, $\mathrm{p}=.626$ ), the path flowing performance orientation to trust in coworkers (standardized estimate .05 , C.R. $=-.74$, $\mathrm{p}=.459$ ), the corridor flowing from performance orientation to instrumental ties (standardized estimate .04, C.R. $=$ $.96, \mathrm{p}=.338$ ), the lane flowing from performance orientation to expressive ties(standardized estimate .06 , C.R. $=.26$, $\mathrm{p}=.792$ ) were not significant.

Table 5-3 Variances

\begin{tabular}{lrrrrr}
\hline & Estimate & S.E. & C.R. & P & Label \\
\hline Learning_orientation &, 395 &, 043 & 9,192 & $* * *$ & \\
Performance_orientation & 1,694 &, 184 & 9,192 & $* * *$ & \\
e1 & 1,245 &, 135 & 9,192 & $* * *$ & \\
e2 &, 538 &, 059 & 9,192 & $* * *$ & \\
e3 &, 792 &, 086 & 9,192 & $* * *$ & \\
e4 &, 900 &, 098 & 9,192 & $* * *$ & \\
e5 &, 762 &, 083 & 9,192 & $* * *$ & \\
\hline
\end{tabular}

In these results, the covariance among variables as shown in the Table 5-3, learning orientation and performance orientation (standardized estimate $.063, \mathrm{C} . \mathrm{R} .=-.239, \mathrm{p}=.811$ ), indicate negative correlations and they are accepted. The suggested hypotheses were tested using t-test, with $95 \%$ confidence interval for all the regression coefficient and the following results were obtained: 


\section{Akmal Hudaykulov, Xu Hongyi, Mostak Ahamed Galib \\ Impact Of Goal Orientation Theory On Social Capital: The Implications For Effective Team Cooperation In Uzbekistan Textile Industry}

Not accepted:

H1 Performance orientation has a negative impact on expressive ties.

H2 Performance orientation has a negative impact on instrumental ties.

H3 Performance orientation has a negative impact on trust.

H4 Performance orientation has a negative impact on identification

H5 Performance orientation has a negative impact on reciprocity

H6 Learning orientation has a positive impact on expressive ties

Accepted:

H7 Learning orientation has a negative impact on instrumental ties.

H8 Learning orientation has a negative impact on trust.

H9 Learning orientation has a negative impact on identification.

H10 Learning orientation has a negative impact on reciprocity.

\section{Discussion and conclusions}

From our study we can conclude that learning orientation has positive impact on almost all elements, for companies which value cooperative behavior during the staffing process, learning oriented people can be chosen to fill in certain positions where social elements are key. Additionally, training programs for boosting learning in companies can be introduced. When it comes to performance orientation it does not have a negative impact on social capital so it does not mean contrary to the current literature (which from we derived our hypotheses) that performance oriented people are detrimental for social capital and ultimately cooperation. However our context is specific given that R\&D staff may perceive performance differently than most workers. They may outperform but at the same time not deviating from the common goal of advancing industry and knowledge. A theoretical understanding of human cooperation helps to answer these applied questions (and the patterns observed in these applications help to validate and extend our theoretical understanding of cooperation). Up to this point no theoretical model was built which has used goal theory to explain social capital. Our findings suggest that there is a significant impact of learning orientation on almost all aspects of social capital. This is completely new notion that our study puts forward. Studies in business and organizational contexts in Uzbekistan are scare. There is no research done on sample of R\&D departments within textile industry. Use of learning and performance orientation to explain social capital in brief context. This is complete new way of looking how certain staffing methods are conducive to build social capital among team members.

Create environment for training and improvement of staff based on practice encouraging interactions in organization through emphasizing significance of social capital. As much as the literature has established the importance of social capital embedded in interpersonal relationships, the present author believes that it is equally useful and important to recognize that social capital and goal orientation can build important relationships through the organizational interventions, which were suggested in the previous section. The formation of social capital depends on the organizational interventions and interaction among the organizational members. Expectation, belief, selfperceptions, goals and intentions give shape and direction to behavior. Human action is viewed as the product of the central role of the cognitive, the self-regulatory and self-efficacy. 


\section{References}

- Adam, F., \& Rončević, B. (2003). Social capital: recent debates and research trends. Social Science Information, 42(2), 155-183.

- Adler, P. S., \& Kwon, S. W. (2002). Social capital: Prospects for a new concept. Academy of management review, 27(1), 17-40.

- Ajzen, I. (1991). The theory of planned behavior. Organizational behavior and human decision processes, 50(2), 179-211.

- Bandura, A. (1990). Perceived self-efficacy in the exercise of control over AIDS infection. Evaluation and program planning, 13(1), 9-17.

- Baruch, Y., \& Lin, C. P. (2012). All for one, one for all: Cooperation and virtual team performance. Technological Forecasting and Social Change, 79(6), 1155-1168.

- Boreham*, N., \& Morgan, C. (2004). A sociocultural analysis of organisational learning. Oxford Review of Education, 30(3), 307-325.

- Bourdieu, P. (2011). The forms of capital.(1986). Cultural theory: An anthology, 81-93.

- Bunderson, J. S., \& Sutcliffe, K. M. (2003). Management team learning orientation and business unit performance. Journal of Applied Psychology,88(3), 552.

- Button, S. B., Mathieu, J. E., \& Zajac, D. M. (1996). Goal orientation in organizational research: A conceptual and empirical foundation.Organizational behavior and human decision processes, 67(1), 26-48.

- Button, Scott B., John E. Mathieu, and Dennis M. Zajac. "Goal orientation in organizational research: A conceptual and empirical foundation."Organizational behavior and human decision processes 67.1 (1996): 26-48.

- DeNisi, A. S., Hitt, M. A., \& Jackson, S. E. (2003). The knowledge-based approach to sustainable competitive advantage. Managing knowledge for sustained competitive advantage: Designing strategies for effective human resource management, 3-33.

- DeShon, R. P., \& Gillespie, J. Z. (2005). A motivated action theory account of goal orientation. Journal of Applied Psychology, 90(6), 1096.

- DeShon, R. P., Kozlowski, S. W., Schmidt, A. M., Milner, K. R., \& Wiechmann, D. (2004). A multiple-goal, multilevel model of feedback effects on the regulation of individual and team performance. Journal of applied psychology, 89(6), 1035.

- Dodgson, M. (1993). Organizational learning: a review of some literatures.Organization studies, 14(3), 375-394.

- Dweck, C. S. (1986). Motivational processes affecting learning. American psychologist, 41(10), 1040.

- Elliot, A. J. (1999). Approach and avoidance motivation and achievement goals. Educational psychologist, 34(3), 169-189.

- Fisher, S. L., \& Ford, J. K. (1998). Differential effects of learner effort and goal orientation on two learning outcomes. Personnel Psychology, 51(2), 397-420.

- Fu, Q. (2004). Trust, social capital and organizational effectiveness (Doctoral dissertation, Virginia Tech).

- Fulkerson, G. M., \& Thompson, G. H. (2008). The Evolution of a Contested Concept: A MetaAnalysis of Social Capital Definitions and Trends (1988-2006)*. Sociological Inquiry, 78(4), 536-557.

- Halpern, D. F. (2005). How time-flexible work policies can reduce stress, improve health, and save money. Stress and Health, 21(3), 157-168.

- Harris, E. G., Mowen, J. C., \& Brown, T. J. (2005). Re-examining salesperson goal orientations: personality influencers, customer orientation, and work satisfaction. Journal of the Academy of Marketing Science, 33(1), 19-35. 
Akmal Hudaykulov, Xu Hongyi, Mostak Ahamed Galib

Impact Of Goal Orientation Theory On Social Capital: The Implications For Effective Team Cooperation In Uzbekistan Textile Industry

- Ifinedo, P. (2012). Understanding information systems security policy compliance: An integration of the theory of planned behavior and the protection motivation theory. Computers \& Security, 31(1), 8395.

- Lesser, E. L. (Ed.). (2000). Knowledge and social capital: Foundations and applications. Routledge.

- Matzler, K., \& Mueller, J. (2011). Antecedents of knowledge sharing-Examining the influence of learning and performance orientation. Journal of Economic Psychology, 32(3), 317-329.

- Meece, J. L., Anderman, E. M., \& Anderman, L. H. (2006). Classroom goal structure, student motivation, and academic achievement. Annu. Rev. Psychol., 57, 487-503.

- Mohan, K., \& Ahlemann, F. (2013). Resistant Use of Project Management Methodologies-Using Psychology to Rethink the Influence of Methodology Attributes. In Wirtschaftsinformatik (p. 100).

- Moorman, R. H., Niehoff, B. P., \& Organ, D. W. (1993). Treating employees fairly and organizational citizenship behavior: Sorting the effects of job satisfaction, organizational commitment, and procedural justice. Employee Responsibilities and Rights Journal, 6(3), 209-225.

- Nicholls, J. G., Cheung, P. C., Lauer, J., \& Patashnick, M. (1989). Individual differences in academic motivation: Perceived ability, goals, beliefs, and values. Learning and individual differences, 1(1), 6384.

- Organ, D. W. (1997). Organizational citizenship behavior: It's construct clean-up time. Human performance, 10(2), 85-97.

- Payne, G. T., Moore, C. B., Griffis, S. E., \& Autry, C. W. (2011). Multilevel challenges and opportunities in social capital research. Journal of Management, 37(2), 491-520.

- Pintrich, P. R. (2003). A motivational science perspective on the role of student motivation in learning and teaching contexts. Journal of educational Psychology, 95(4), 667.

- Portes, A. (2000, March). The two meanings of social capital. In Sociological forum (Vol. 15, No. 1, pp. 1-12). Kluwer Academic Publishers-Plenum Publishers.

- Putnam, R. D. (1995). Tuning in, tuning out: The strange disappearance of social capital in America. PS: Political science \& politics, 28(04), 664-683.

- Ryan, R. M., \& Deci, E. L. (2000). Intrinsic and extrinsic motivations: Classic definitions and new directions. Contemporary educational psychology, 25(1), 54-67.

- Sampson, R. J., Morenoff, J. D., \& Earls, F. (1999). Beyond social capital: Spatial dynamics of collective efficacy for children. American sociological review, 633-660.

- Sampson, R. J., Morenoff, J. D., \& Gannon-Rowley, T. (2002). Assessing" neighborhood effects": Social processes and new directions in research.Annual review of sociology, 443-478.

- Sandefur, R. L., \& Laumann, E. O. (1998). A paradigm for social capital.Rationality and society, 10(4), 481-501.

- Sinkula, J. M., Baker, W. E., \& Noordewier, T. (1997). A framework for market-based organizational learning: Linking values, knowledge, and behavior. Journal of the academy of Marketing Science, 25(4), 305-318.

- Stewart, G. L., \& Barrick, M. R. (2000). Team structure and performance: Assessing the mediating role of intrateam process and the moderating role of task type. Academy of management Journal, 43(2), 135-148.

- VandeWalle, D., Cron, W. L., \& Slocum Jr, J. W. (2001). The role of goal orientation following performance feedback. Journal of Applied Psychology,86(4), 629. 
Akmal Hudaykulov, Xu Hongyi, Mostak Ahamed Galib

Impact Of Goal Orientation Theory On Social Capital: The Implications For Effective Team Cooperation In Uzbekistan Textile Industry

\section{Questionnaire}

Learning orientation

Making a tough project is very satisfying
An important part of being a good
employee is continually improving our
skills
I put in a great deal of effort sometimes
in order to learn something new

Performance orientation

I feel very good when I know I have
outperformed other employees
I always try to communicate my
accomplishments to my manager
Ispend a lot of time thinking about how
my performance compares with others

\section{Identification}

I feel a sense of belonging towards the
project team
I have the feeling of togetherness or
closeness in the project team agree
I have a strong positive feeling towards
the project team
I am proud to be a member of the project
team

Instrumental ties 
Akmal Hudaykulov, Xu Hongyi, Mostak Ahamed Galib

Impact Of Goal Orientation Theory On Social Capital: The Implications For Effective Team Cooperation In Uzbekistan Textile Industry

In the office/lab, my co-workers and I
exchange advice.
My co-workers and I offer assistance
with one another during office hours
My co-workers and I get along well in the
office/lab
My co-workers and I make a good team
for coordination in the office/lab.

Expressive ties

I am well acquainted personally with my
co-workers
I talk with co-workers about things
beyond work
I have lunch with my co-workers during
break hours.
I consult my co-worker for personal
matters.

\section{Reciprocity}

I know that other project team members
will help me, so it's only fair to help other
members.
I believe that project team members
would help me if I need it.

\section{Trust in coworkers}

I consider my co-workers on the project
as people who( $\mathrm{m})$ can be trusted
I consider my co-workers on the project
as people who(m) can be counted on to
do what is right
I consider my co-workers on the project
as people who(m) can be counted on to
get the job done right
I consider my co-workers on the project
as people who(m) are always faithful
I consider my co-workers on the project
as people who(m) I have great
confidence in.

